\title{
Effect of Polyunsaturated Fatty Acid (PUFA) Supplementation on Intestinal Inflammation and Necrotizing Enterocolitis (NEC) in a Neonatal Rat Model
}

\author{
MICHAEL S. CAPLAN, TANYA RUSSELL, YU XIAO, MICHAEL AMER, SUSAN KAUP, \\ AND TAMAS JILLING
}

Department of Pediatrics, Evanston Northwestern Healthcare, Northwestern University Medical School, Evanston, Illinois 60201, U.S.A. [M.S.C., T.R., Y.X., M.A., T.J.]; and Wyeth Nutritionals International, Radnor, Pennsylvania 10987, U.S.A. [S.K.]

\begin{abstract}
Inasmuch as long-chain polyunsaturated fatty acids (PUFA, metabolites of the essential n-3 and n-6 fatty acids) are known to modulate inflammation, we hypothesized that supplementation of formula with these compounds would prevent necrotizing enterocolitis (NEC) and intestinal inflammation in our neonatal rat model. Newborn rats were stressed with asphyxia and formula feeding, and randomly assigned to control formula, control with PUFA supplementation, and PUFA with nucleotides. Animals were followed for 72-96 h and assessed for death, gross and histologic NEC, intestinal apoptosis, endotoxemia, and intestinal mRNA synthesis of phospholipase $\mathrm{A}_{2}$-II (rate-limiting enzyme for platelet activating factor production), platelet activating factor receptor, and inducible nitric oxide synthase. We found that PUFA reduced the incidence of death and NEC compared with the other groups (NEC 8 of 24 versus 17 of 24 control and 13 of 23 PUFA + nucleotides, $p<0.05)$. Furthermore, PUFA reduced plasma endotoxemia at $48 \mathrm{~h}(25 \pm 4 \mathrm{EU} / \mathrm{mL}$ versus $276 \pm 39$ $\mathrm{EU} / \mathrm{mL}$ in control and $170 \pm 28 \mathrm{EU} / \mathrm{mL}$ in PUFA + nucleotide), intestinal phospholipase $\mathrm{A}_{2}$-II expression at $24 \mathrm{~h}$, and platelet activating factor receptor expression at $48 \mathrm{~h}$. Formula supple-
\end{abstract}

\section{ABSTRACT}

mentation had no effect on apoptosis of intestinal epithelium or intestinal inducible nitric oxide synthase expression. Addition of nucleotides with PUFA abrogated the beneficial effects of PUFA on intestinal inflammation. We conclude that PUFA reduces the incidence of NEC and intestinal inflammation in a neonatal rat model. (Pediatr Res 49: 647-652, 2001)

\section{Abbreviations:}

PUFA, polyunsaturated fatty acids

NEC, necrotizing enterocolitis

$\mathbf{P L A}_{2}$, phospholipase $\mathrm{A}_{2}$-II

AA, arachidonic acid

DHA, docosahexaenoic acid

PAF, platelet activating factor

iNOS, inducible nitric oxide synthase

TdT, deoxynucleotidyl transferase

LAL, Limulus amebocyte lysate

RT-PCR, reverse transcriptase PCR

TUNEL, terminal deoxynucleotidyl transferase-mediated dUTP nick-end labeling
NEC is an overwhelming gastrointestinal emergency that primarily afflicts extremely low birth weight infants after the initiation of enteral feeding (1). The National Institute of Child Health and Human Development Network data show that despite improvements in many aspects of neonatal care, the incidence and severity of NEC has remained unchanged (2). Several clinical and basic science reports have identified that activation of the inflammatory cascade after the risk factors of

Received September 28, 2000; accepted December 20, 2000.

Correspondence and reprint requests: Michael Caplan, M.D., Department of Pediatrics, Evanston Northwestern Healthcare, 2650 Ridge Ave., Evanston, IL 60201, U.S.A.; e-mail: mca113@northwestern.edu

Supported in part by Wyeth Nutritionals International, the Jessica J. Golder Endowment (T.J.), and The March of Dimes Birth Defects Foundation (M.C.). ischemia-hypoxia, feeding, and bacterial colonization results in the final common pathway of intestinal necrosis that may occur in this high-risk population (3-5). Additional human and animal experimentation has defined an important association with the phospholipid inflammatory mediator PAF in the pathophysiology of NEC (6-8). Studies in our laboratory using a well-described neonatal rat model have shown that PAF receptor blockade or enhanced intestinal PAF degradation via the enzyme PAF-acetylhydrolase reduces the incidence of NEC, thus emphasizing the importance of endogenous PAF in the cause $(9,10)$.

Besides prematurity, the most consistent and important risk factor for NEC is enteral feeding. Although studies suggest that 90 to $95 \%$ of neonates in whom NEC develops have received 
enteral nutrition, additional analyses have shown that the incidence is lower in neonates fed breast milk compared with formula (11). Breast milk contains several bioactive factors that are not present in premature infant formula, and it is theorized that these components down-regulate the inflammatory cascade, thus altering the incidence or course of neonatal NEC (12-14). Recently, PUFA have generated significant interest because of their potential effects on neonatal nutrition, visual acuity, and intelligence in developing infants (15-17). Additionally, these compounds are thought to influence prostaglandin metabolism and cytokine activation, and have been associated with a reduction in neonatal NEC in a prospective supplementation trial of premature infants (18). Therefore, we hypothesized that PUFA supplementation of formula in our neonatal rat model of NEC may reduce the incidence of disease, and we designed this study to further characterize the effects of these compounds on the metabolism of PAF and other markers of intestinal inflammation.

\section{METHODS}

Animal model. Neonatal Sprague-Dawley rats were delivered via abdominal incision from time-dated pregnant females (Harlan, Inc, Indianapolis, IN, U.S.A.) on the 21 st day of gestation using $\mathrm{CO}_{2}$ anesthesia (60 $\mathrm{s}$ in a precharged chamber). Neonatal animals were recovered, dried, and warmed in a neonatal incubator (Airshields, Hatboro, PA, U.S.A.) at $37^{\circ} \mathrm{C}$ at maximal humidity. Animals were delivered in this fashion to prevent any maternal milk exposure, a factor that impacts on the development of NEC. To increase the susceptibility to NEC, neonatal animals were exposed to asphyxia twice daily using $100 \%$ nitrogen for $50 \mathrm{~s}$ followed by exposure to cold $\left(4^{\circ} \mathrm{C}\right.$ for $\left.10 \mathrm{~min}\right)$. Control animals were fed using S-26/SMA premature formula (Wyeth Nutritionals International, Radnor, PA, U.S.A.) concentrated to provide $200 \mathrm{kcal} / \mathrm{kg} / \mathrm{d}$ with an orogastric feeding tube (1.9F Silastic catheter, Bard, Salt Lake City, UT, U.S.A.) beginning with $0.1 \mathrm{~mL} / 3 \mathrm{~h}$ and advanced to $0.3 \mathrm{~mL} / 3 \mathrm{~h}$ by $72 \mathrm{~h}$ of life. Using this protocol of asphyxia and formula feeding, approximately $75 \%$ of neonatal rats develop clinical and pathologic signs of NEC by $72 \mathrm{~h}$ of life, including abdominal distention, bloody stools, vomiting, respiratory distress, gross hemorrhagic intestinal necrosis, and histologic signs varying between midvillous necrosis and transmural necrosis (19).

To investigate the effect of PUFA supplementation of neonatal formula on the pathophysiology of NEC, animals were divided into the following experimental groups: group A, control formula with S-26/SMA at $200 \mathrm{kcal} / \mathrm{kg} / \mathrm{d}$; group B, formula with PUFA supplementation containing $34 \mathrm{mg} / 100$ $\mathrm{mL} \mathrm{AA}$ and $23 \mathrm{mg} / 100 \mathrm{~mL}$ DHA to provide an AA/DHA ratio of 1.5:1.0; and group C, formula with PUFA supplementation (identical to group B above) and nucleotide supplementation. Nucleotides were supplemented to approximate human milk at the following concentrations $(\mathrm{mg} / 100 \mathrm{~g}$ formula powder/200 $\mathrm{mL}$ water): CMP 15.62 versus 3.55 control, UMP 9.2 versus 6.2 control, IMP 3.06 versus 0.73 control, GMP 2.08 versus 0.2 control, and AMP 3.57 versus 0.18 control. Nucleotides were given with PUFA in an additional experimental group because
1) studies have shown nutritional and anti-inflammatory benefits from these compounds that are present in human milk (20, 21), and 2) nucleotides have been added to the composition of most neonatal formulas. All three formulas were premixed in powder form and reconstituted with water $(100 \mathrm{~g}$ powder with $200 \mathrm{~mL}$ water) at the beginning of the experimental protocol, and the contents of each were unknown to the research technicians and the principal investigators until the completion of the study.

Animals were monitored until 72-96 h of life for clinical signs of NEC; moribund animals unable to eat or with signs of respiratory distress were euthanized, and intestines were frozen for subsequent analysis. In additional groups of animals, neonates were euthanized at 24 or $48 \mathrm{~h}$ of life to investigate pathophysiologic mechanisms related to NEC, including intestinal apoptosis, plasma endotoxemia, and intestinal tissue gene expression of key mediators implicated in NEC, namely $\mathrm{PLA}_{2}$, iNOS, and PAF receptor. This protocol was reviewed and approved by the Institutional Animal Care and Use Committee of Evanston Northwestern Healthcare.

Evaluation of NEC. At euthanasia, the intestine was observed grossly for the presence of hemorrhagic necrosis, and scored as none, mild (occasional areas of violaceous, inflamed mucosa), moderate (multiple areas of necrosis), or severe (extensive necrosis occupying $>50 \%$ of the intestinal length). Subsequently, specimens were placed in $10 \%$ formalin and fixed for subsequent histologic analysis, and scored as 0 (normal villi), 1 (epithelial cell sloughing), 2 (midvillous necrosis), 3 (complete villous necrosis), or 4 (transmural necrosis).

Fluorescence TUNEL staining. Although there are several approaches to quantify apoptosis, studies of animal tissues are best accomplished using a TUNEL stain in situ technique (22). The principle of this procedure rests on the fact that endonucleolytic degradation of chromatin into discrete DNA fragments (which is the hallmark of apoptosis) allows incorporation of fluorescein-nucleotide conjugates at the 3'-OH end of DNA under the influence of TdT. In short, intestine is formalin-fixed, paraffin-embedded, and cut onto a slide. Subsequently the slide is deparaffinized, treated with proteinase $\mathrm{K}$ to improve permeability, and TdT enzyme added along with nucleotide mix including fluorescein-dUTP conjugate. Equilibration buffer is applied, and the reaction is stopped after $1 \mathrm{~h}$. After labeling, preparations are washed, nuclei are counterstained with HOE33258, and then slides are mounted with antifade reagent (Molecular Probes, Eugene, OR, U.S.A.). Each sample is run with a TdT negative control to ensure reliability of positively stained apoptotic bodies. Slides are examined with fluorescence digital imaging and assessed as mild (1, tips of villi), moderate (2, apoptotic fragments in midvilli), or severe (3, extensive apoptosis throughout villi).

Endotoxin assay. Plasma endotoxin was assessed using a spectrophotometric method provided in an LAL assay commercially available (Biowhittaker, Walkersville, MD, U.S.A.). Briefly, endotoxin catalyzes the activation of a proenzyme in $\mathrm{LAL}$, and the rate of activation is determined by the concentration of endotoxin present. The endotoxin in a sample is compared with that obtained from a standard curve of Escherichia coli endotoxin supplied by the company. 
RT-PCR for PLA, PAF-receptor, and iNOS. Total RNA was isolated from frozen tissues using RNA STAT-60 following the manufacturer's instructions, TEL-TEST, INC, Friendswood, TX, U.S.A. Genomic DNA, a possible impurity in the RNA extract, was subsequently removed by adding RNase-free DNase. RNA integrity was verified by electrophoresis on $1 \%$ formaldehyde-agarose gel. Semiquantitative RT-PCR was performed by placing 1-2 $\mu \mathrm{g}$ of newborn rat intestine total RNA into tubes containing $1.0 \mu \mathrm{L}$ of reverse transcription reaction mixture $\left(1 \times \mathrm{rTth}\right.$ reverse transcription buffer, $1 \mathrm{mM} \mathrm{MnCl}{ }_{2}$, $2.5 \mathrm{U}$ rTth DNA polymerase, $200 \mu \mathrm{M}$ each dNTP, and $1 \mu \mathrm{M}$ antisense primer: for $\mathrm{PLA}_{2}$, or random hexamers for iNOS and for $\beta$-actin. The mixture was incubated at $37^{\circ} \mathrm{C}$ for $60 \mathrm{~min}$, then terminated on ice. The PCR reaction was performed in 50 $\mu \mathrm{L}$ of PCR mixture $\left(1 \times\right.$ chelating buffer, $2.5 \mathrm{mM} \mathrm{MgCl}_{2}$, and $0.5 \mu \mathrm{M}$ following primers: 5'-TGACAGCATGAAGGTCCTCC-3'/5'-TGGCATCCTTGGGGGATCCT-3' for PLA ${ }_{2}$-II, 5'-ATGGCTTGCCCTTGGAAGTTTCTC-3'/5'-TCCAGGCCATCTTGGTGGCAAAGA-3' for iNOS, 5'-AAGTTCCGGAAGCACCTCAGCG-3'/5'-TTAATTTTTCAATGGCAGGAC-3' for PAF receptor, or 5'-GATCTTGATCTTCATGGTGCTAGG-3'/5'-TTGTAACCAACTGGGACGATATGG-3' for $\beta$-actin. Reaction conditions were optimized for each mRNA species to ensure that the amplification was in the linear phase. After the PCR amplification, the DNA products are separated by electrophoresis on $2 \%$ agarose gel containing SYBR Green I (Molecular Probes, Eugene, OR, U.S.A.). The density of each DNA band was evaluated with Storm Phosphorimager (Molecular Dynamics, Sunnyvale, CA, U.S.A.) and analyzed by a computer software ImageQuant (Molecular Dynamics, Sunnyvale, CA, U.S.A.). Ratios between band intensities of $\mathrm{PLA}_{2} / \beta$ actin and iNOS $/ \beta$-actin were determined.

Statistics. $\chi^{2}$ analysis using a $3 \times 2$ model was performed to analyze differences in groups for NEC outcome. Comparisons among the three groups for continuous data were performed using ANOVA. For all analyses, $p<0.05$ was considered significant.

\section{RESULTS}

Animals supplemented with PUFA had a significantly lower incidence of gross and microscopic NEC (8 of 24) compared with controls (17 of 24) and with pups supplemented with PUFA and nucleotides (13 of 23; $p<0.05$; Table 1). Animals that developed intestinal necrosis typically became ill between 36 and $72 \mathrm{~h}$ of life, and showed signs of frequent vomiting, abdominal distension, bloody stools, and respiratory distress. The gross intestinal examination revealed segmental hemorrhagic necrosis in most animals with rare pups exhibiting

Table 1. Effect of PUFA and PUFA + nucleotides on NEC and death in a neonatal rat model

\begin{tabular}{lccc}
\hline \multicolumn{1}{c}{ List } & Histologic NEC & Gross NEC & Death \\
\hline No supplement & $17 / 24$ & $14 / 24$ & $17 / 24$ \\
PUFA & $8 / 24^{*}$ & $7 / 24^{*}$ & $8 / 24^{*}$ \\
PUFA + nucleotides & $13 / 23$ & $12 / 23$ & $12 / 23$ \\
\hline$* p<0.05$ & & &
\end{tabular}

almost complete small intestinal necrosis. Microscopic abnormalities were found in all animals with evidence of gross necrosis; however, the stage of histologic injury did not always correlate with the extent (length of bowel) of gross findings (Fig. 1). All animals that died before the end of the study protocol (96 h) showed histologic signs of intestinal necrosis in this study, whereas a few had no identifiable macroscopic lesions.

Supplementation with PUFA with or without nucleotides did not affect the initiation of apoptosis in intestinal epithelium by 48 to $72 \mathrm{~h}$ in this study. By $48 \mathrm{~h},>50 \%$ of animals showed significant apoptotic activity characterized by abundant TUNEL-positive fluorescence at the midvillus level; however, $<25 \%$ had histologic signs of NEC on microscopic analysis. There were no differences among groups in degree of apoptosis or extent at any time points studied ( $48 \mathrm{~h}$ median scores group $\mathrm{A}, 1.8 ; \mathrm{B}, 2.1$; and $\mathrm{C}, 1.9$ ).

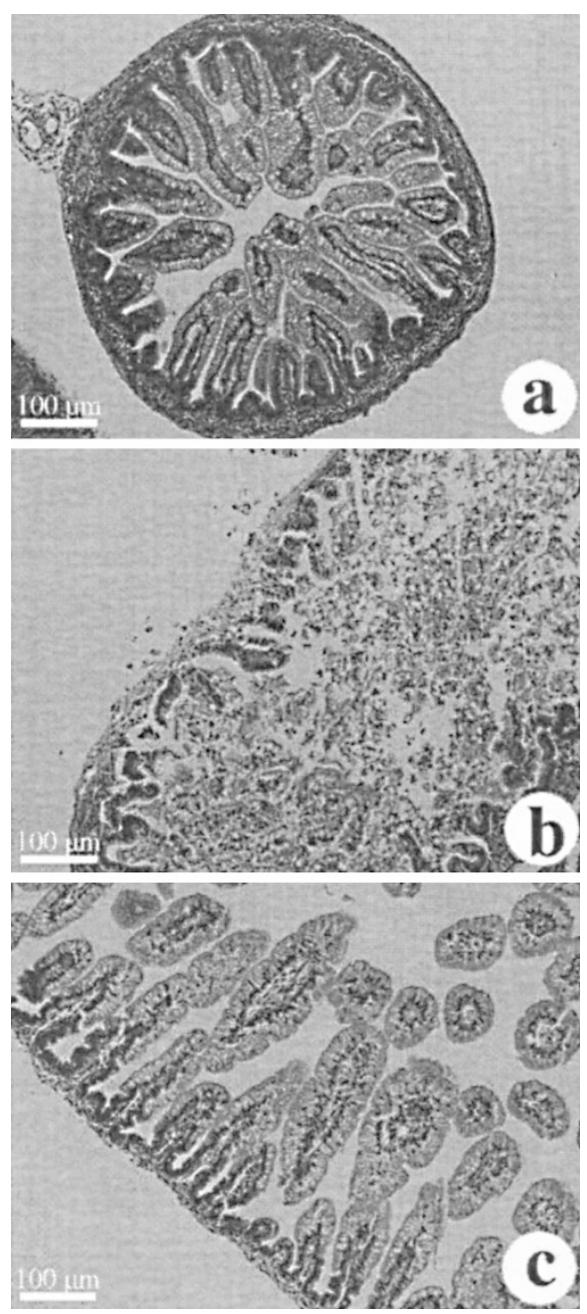

Fig. 1. PUFA supplementation reduced the severity of histologic NEC. Animals were treated and assigned to different treatment groups as described in Methods. Animals were killed at $48 \mathrm{~h}$ of life, and formalin-fixed, paraffinembedded intestines were sectioned and stained with hematoxylin and eosin. Images shown are representative micrographs of hematoxylin and eosinstained sections of the small intestine from mother-fed animals $(a)$, formulafed and cold-asphyxia-stressed animals $(b)$, and from cold-asphyxia-stressed animals that were fed with PUFA-supplemented formula $(c)$. 
Plasma endotoxemia was similar among all three groups at $24 \mathrm{~h}$, but significantly reduced in animals supplemented with PUFA by $48 \mathrm{~h}$ of life (Fig. 2).

Intestinal $\mathrm{PLA}_{2}$ gene expression was decreased in PUFAsupplemented animals at $24 \mathrm{~h}$, but similar in PUFA + nucleotide animals compared with controls. There were no differences among groups at $48 \mathrm{~h}$ in $\mathrm{PLA}_{2}$ mRNA expression (Fig. $3)$.

Expression of intestinal PAF receptor was reduced in the PUFA-supplemented group at $48 \mathrm{~h}$ compared with control and PUFA + nucleotide groups $(1.51 \pm 0.27$ ratio to $\beta$-actin versus $1.91 \pm 0.23$ and $2.10 \pm 0.20 ; p<0.05$ ), but no different at $24 \mathrm{~h}$ (Fig. 4). Analysis of intestinal iNOS mRNA revealed similar results among all groups at 24- and 48-h time points (Fig. 5).

\section{DISCUSSION}

Our results indicate that PUFA supplementation of neonatal formula in this rat model of NEC reduces the incidence of intestinal necrosis. Additional outcome analyses in our study suggest that PUFA reduce the intestinal expression of the PAF-synthesizing enzyme PLA $\mathrm{P}_{2}$ and the PAF receptor, and decrease plasma endotoxemia, but have no effect on apoptosis of intestinal epithelium or gene expression of intestinal iNOS. Although our data support the clinical findings recently reported on PUFA supplementation in premature infants (18), they provide new insights into the mechanisms responsible for these beneficial effects.

Although premature neonates appear to synthesize longchain PUFA from essential fatty acid precursors, they may require dietary supplementation to attain normal tissue concentrations of omega-3 and omega- 6 fatty acids $(23,24)$. In addition, these long-chain PUFA are present in breast milk, and nursing infants absorb significant quantities during the first 4 to 6 mo of life (25). Although deficiency of essential fatty acids results in abnormal growth and CNS development, supplementation of neonatal formula with AA and DHA has been associated with improved visual acuity and mental development in several recent studies $(26,27)$. Furthermore, in a recent randomized trial examining the role of PUFA supplementation of

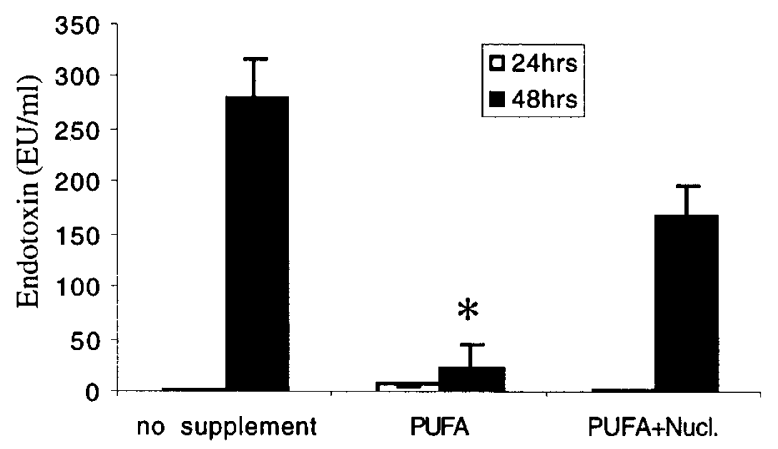

Fig. 2. The effect of PUFA on plasma endotoxin levels. Serum samples were collected from animals at 24 or $48 \mathrm{~h}$ of life. Endotoxin levels were determined from serum samples using the LAL method. Data shown are mean \pm SEM endotoxin levels at the time points and categories as indicated on the figure $(n$ $=8 /$ group for each time point). ${ }^{*}$ denotes statistically significant difference from the no supplement group.

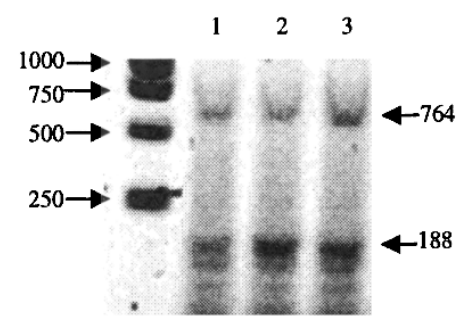

a

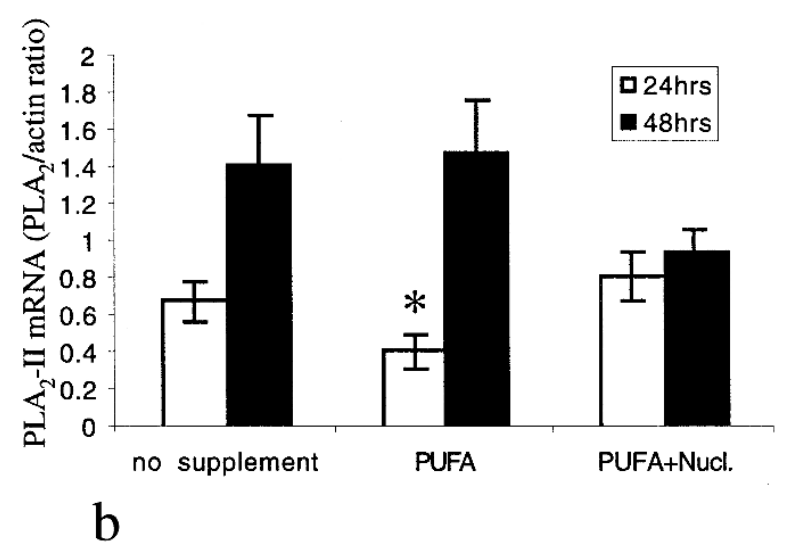

Fig. 3. Effect of PUFA on PLA $\mathrm{PLN}_{2}$ mRA expression in the bowel. Intestines were harvested from animals after euthanasia at 24 or $48 \mathrm{~h}$ of life. PLA 2 mRNA levels were determined from RNA isolated from intestines using semiquantitative RT-PCR as described in the Methods. (a) representative image illustrating agarose gel electrophoresis of $\mathrm{PLA}_{2}$ and $\beta$-actin PCR products from samples taken at $48 \mathrm{~h}$. The 764-bp band corresponds to $\beta$-actin and the 188-bp band corresponds to $\mathrm{PLA}_{2}$. Lane 1, mother-fed control animal; lane 2, formula-fed and cold-asphyxia-stressed animal with no formula supplement; and lane 3, formula-fed and cold-asphyxia-stressed animal with PUFA supplement. $(b)$ mean \pm SEM PLA 2 mRNA levels at the time points and categories indicated on the figure ( $n=6$ /group at each time point). *represents statistically significant difference from the no supplement group.

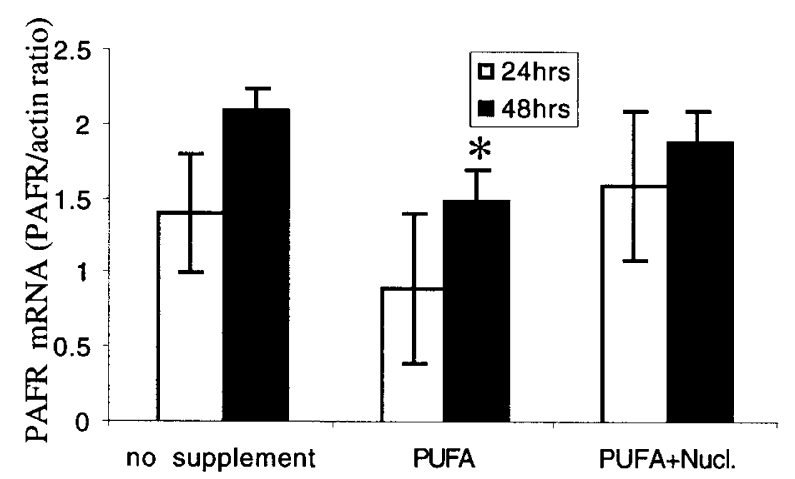

Fig. 4. Effect of PUFA on PAF receptor $(P A F R)$ mRNA expression in the bowel. Intestines were harvested from animals after euthanasia at 24 or $48 \mathrm{~h}$ of life. PAFR mRNA levels were determined from RNA isolated from intestines using semiquantitative RT-PCR as described in the Methods. Mean \pm SEM PAFR mRNA levels at the time points and categories indicated on the figure ( $n=6$ /group for each time point). *indicates statistically significant difference from the no supplement group.

premature formula on neonatal CNS development and visual function, Carlson et al. (18) found that PUFA supplementation significantly reduced the incidence of NEC in the treated group of premature infants. These findings and others have suggested 


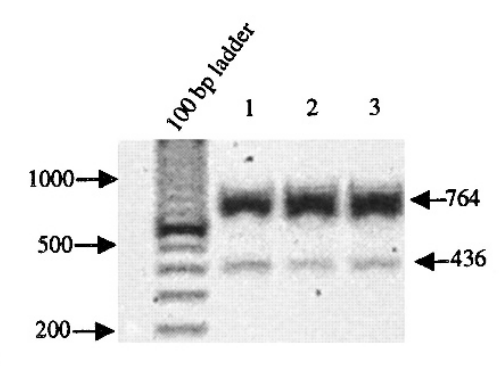

a

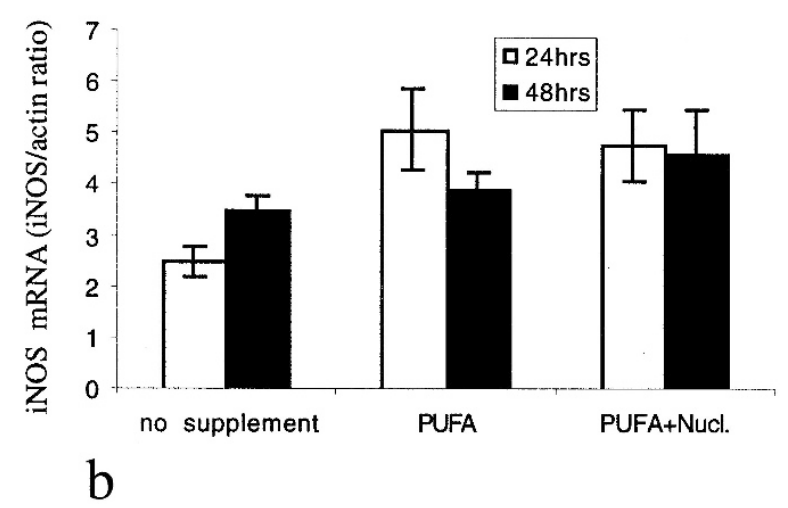

Fig. 5. Effect of PUFA on iNOS mRNA expression in the bowel. Intestines were harvested from animals after euthanasia at 24 or $48 \mathrm{~h}$ of life. iNOS mRNA levels were determined from RNA isolated from intestines using semiquantitative RT-PCR as described in the Methods. (a) representative image illustrating agarose gel electrophoresis of iNOS and $\beta$-actin PCR products from samples taken at $48 \mathrm{~h}$. The 764-bp band corresponds to $\beta$-actin and the 436-bp band corresponds to iNOS (1:10 dilution). Lane 1, mother-fed control animal; lane 2, formula-fed and cold-asphyxia-stressed animal with no formula supplement; and lane 3, formula-fed and cold-asphyxia-stressed animal with PUFA supplement. (b) data shown are mean \pm SEM iNOS mRNA levels at the time points and categories indicated on the figure $(n=6 /$ group for each time point).

that PUFA may modulate the inflammatory response in several tissues, including the intestine, and may therefore act as a beneficial supplement of preterm formula for NEC prevention.

The possible mechanisms whereby PUFA influence the inflammatory cascade are numerous. Studies have suggested that fish oil or other long-chain PUFA supplementation modulates the production or effects of cytokine mediators (28), prostaglandin metabolites. including thromboxanes and leukotrienes (29), signal transduction proteins. including protein kinase C (30), cellular transport proteins (magnesium-ATPase) (31), and transcription factors. such as NF- $\kappa \mathrm{B}$ (32). Nonetheless, the specific role of these compounds in modulating gut inflammation (if there are true effects) remains unclear. A recent study using a short-term hypoxia-induced model of NEC in mice has shown that fish oil supplementation (primarily omega-3 fatty acids) reduced intestinal necrosis while decreasing intestinal PAF and leukotriene concentrations in treated animals (33). Our study shows a clear reduction of intestinal inflammation and necrosis with AA and DHA supplementation, and decreased $\mathrm{PLA}_{2}$ gene expression at $24 \mathrm{~h}$, the rate-limiting enzyme for PAF biosynthesis. These results extend the work of Akisu et al. (33) in that reduced intestinal PAF concentrations result from decreased $\mathrm{PLA}_{2}$ gene expression. Additionally, we found that PUFA supplementation attenuated PAF receptor expression in stressed intestinal homogenates, thereby reducing the theoretical PAF effect on gut epithelium after accelerated PAF production during stress. Similar to our previous studies, changes in PAF-related gene expression predated the onset of intestinal injury, but occurred simultaneously with the rise in endotoxemia, thereby supporting a role for altered mucosal permeability in the pathophysiology. Whereas in previous studies of newborn rat NEC we have shown that iNOS expression (34) and apoptosis (unpublished observations) are accelerated after formula feeding and asphyxia, the PUFA supplementation in this trial had no effect on these outcomes. Thus, the beneficial effects of PUFA on intestinal health may act on epithelial cell integrity by 1 ) reducing bacterial or endotoxin translocation, or 2) reducing mucosal PAF synthesis and receptor activation, thereby modulating the direct effects of PAF on intestinal epithelium. As such, PAF has been shown to directly increase mucosal permeability $(35,36)$ and is known to stimulate the activation of several potent second messengers of inflammation (37-39). In addition, recent observations from our laboratory in vitro have shown that PAF directly stimulates chloride transport in intestinal epithelium via activation of a mucosal PAF receptor, leading to intracellular acidosis and subsequent cellular dysfunction. In summary, PUFA supplementation modulates PAF metabolism and endotoxin translocation, and these mechanisms may in part explain the beneficial effect of these compounds observed in humans and animals on intestinal necrosis. Nonetheless, additional studies evaluating the effect of PUFA supplementation on production and activity of intestinal mediators (cytokines, including IL-1, -6, -10 , and -11 , and prostaglandin metabolites) would be worthwhile.

Dietary nucleotides are another group of bioactive molecules that are present in human milk, and have recently been added to many term and preterm formula preparations. Nucleotides have been shown to modulate the humoral and cellular immune response in supplemented infants $(20,21)$, and therefore may modulate the inflammatory response to pathogens in the intestinal milieu. Therefore, although the aim of this study was not to evaluate the role of nucleotides on intestinal inflammation or necrosis, we included a study group of PUFA and nucleotide supplementation inasmuch as premature infants will likely be exposed to both preparations, and the presence of nucleotides could influence PUFA effects. Surprisingly, we found that nucleotide supplementation abrogated the beneficial effects of PUFA supplementation on death, intestinal necrosis, endotoxemia, and $\mathrm{PLA}_{2}$ and PAF receptor mRNA expression in our neonatal model. Although the findings suggest that nucleotides may attenuate the effects of PUFA on intestinal inflammation, additional studies are required to clarify any specific role they may play in intestinal inflammation and health.

In conclusion, PUFA supplementation significantly reduced the incidence of NEC in the neonatal rat model while downregulating PAF production, PAF receptor synthesis, and endotoxin translocation into the systemic circulation. Although these data support the results of a prospective trial in preterm infants, a larger randomized, controlled trial of PUFA supple- 
mentation in premature formula to prevent NEC seems warranted.

\section{REFERENCES}

1. Kliegman RM, Fanaroff AA 1984 Necrotizing enterocolitis. N Engl J Med 310:10931103

2. Uauy RD, Fanaroff AA, Korones SB, Phillips EA, Phillips JB, Wright LL 1991 Necrotizing enterocolitis in very low birth weight infants: biodemographic and clinical correlates. National Institute of Child Health and Human Development Neonatal Research Network. J Pediatr 119:630-638

3. Nanthakumar NN, Fusunyan RD, Sanderson I, Walker WA 2000 Inflammation in the developing human intestine: a possible pathophysiologic contribution to necrotizing enterocolitis. Proc Natl Acad Sci U S A 97:6043-6048

4. Kliegman RM 1990 Models of the pathogenesis of necrotizing enterocolitis. J Pediatr 117 (suppl): S2-S5

5. Caplan MS, MacKendrick W 1993 Necrotizing enterocolitis: a review of pathogenetic mechanisms and implications for prevention. Pediatr Pathol 13:357-369

6. Caplan M, Hsueh W, Kelly A, Donovan M 1990 Serum Paf acetylhydrolase increases during neonatal maturation. Prostaglandins 39:705-714

7. Hsueh W, Caplan MS, Sun X, Tan X, MacKendrick W, Gonzalez-Crussi F 1994 Platelet-activating factor, tumor necrosis factor, hypoxia and necrotizing enterocolitis. Acta Paediatr Suppl 396:11-17

8. Gonzalez-Crussi F, Hsueh W 1983 Experimental model of ischemic bowel necrosis The role of platelet-activating factor and endotoxin. Am J Pathol 112:127-135

9. Caplan MS, Hedlund E, Adler L, Lickerman M, Hsueh W 1997 The plateletactivating factor receptor antagonist WEB 2170 prevents neonatal necrotizing enterocolitis in rats. J Pediatr Gastroenterol Nutr 24:296-301

10. Caplan MS, Lickerman M, Adler L, Dietsch GN, Yu A 1997 The role of recombinant platelet-activating factor acetylhydrolase in a neonatal rat model of necrotizing enterocolitis. Pediatr Res 42:779-783

11. Lucas A, Cole TJ 1990 Breast milk and neonatal necrotising enterocolitis. Lance 336:1519-1523

12. Schanler RJ, Atkinson SA 1999 Effects of nutrients in human milk on the recipient premature infant. J Mammary Gland Biol Neoplasia 4:297-307

13. Hanson LA 1999 Human milk and host defence: immediate and long-term effects. Acta Paediatr Suppl 88:42-46

14. Walker WA 1997 Breast milk and the prevention of neonatal and preterm gastrointestinal disease states: a new perspective. Chung Hua Min Kuo Hsiao Erh Ko I Hsueh Hui Tsa Chih 38:321-331

15. Gibson RA, Makrides M 1998 The role of long chain polyunsaturated fatty acids (LCPUFA) in neonatal nutrition. Acta Paediatr 87:1017-1022

16. Carlson SE 1999 Long-chain polyunsaturated fatty acids and development of human infants. Acta Paediatr Suppl 88:72-77

17. Uauy R, Hoffman DR 2000 Essential fat requirements of preterm infants. Am J Clin Nutr 71 (suppl): 245S-250S

18. Carlson SE, Montalto MB, Ponder DL, Werkman SH, Korones SB 1998 Lower incidence of necrotizing enterocolitis in infants fed a preterm formula with egg phospholipids. Pediatr Res 44:491-498

19. Caplan MS, Hedlund E, Adler L, Hsueh W 1994 Role of asphyxia and feeding in a neonatal rat model of necrotizing enterocolitis. Pediatr Pathol 14:1017-1028
20. Carver JD, Pimentel B, Cox WI, Barness LA 1991 Dietary nucleotide effects upon immune function in infants. Pediatrics 88:359-363

21. Pickering LK, Granoff DM, Erickson JR, Masor ML, Cordle CT, Schaller JP, Winship TR, Paule CL, Hilty MD 1998 Modulation of the immune system by human milk and infant formula containing nucleotides. Pediatrics 101:242-249

22. Gavrieli Y, Sherman Y, Ben-Sasson SA 1992 Identification of programmed cell death in situ via specific labeling of nuclear DNA fragmentation. J Cell Biol 119:493-501

23. Clandinin MT, Chappell JE, Leong S, Heim T, Swyer PR, Chance GW 1980 Intrauterine fatty acid accretion rates in human brain: implications for fatty acid requirements. Early Hum Dev 4:121-129

24. Uauy R, Mena P 1999 Requirements for long-chain polyunsaturated fatty acids in the preterm infant Curr Opin Pediatr 11:115-120

25. Gibson RA, Neumann MA, Makrides M 1997 Effect of increasing breast milk docosahexaenoic acid on plasma and erythrocyte phospholipid fatty acids and neural indices of exclusively breast fed infants. Eur J Clin Nutr 51:578-584

26. Birch DG, Birch EE, Hoffman DR, Uauy RD 1992 Retinal development in very-lowbirth-weight infants fed diets differing in omega-3 fatty acids. Invest Ophthalmol Vis Sci 33:2365-2376

27. Carlson SE, Werkman SH, Tolley EA 1996 Effect of long-chain n-3 fatty acid supplementation on visual acuity and growth of preterm infants with and without bronchopulmonary dysplasia. Am J Clin Nutr 63:687-697

28. Blok WL, Katan MB, van der Meer JW 1996 Modulation of inflammation and cytokine production by dietary (n-3) fatty acids. J Nutr 126:1515-1533

29. Huang MC, Craig-Schmidt MC 1996 Arachidonate and docosahexaenoate added to infant formula influence fatty acid composition and subsequent eicosanoid production in neonatal pigs. J Nutr 126:2199-2208

30. Rise P, Galli C 1999 Arachidonic and docosahexaenoic acids differentially affect the expression of fatty acyl-CoA oxidase, protein kinase $\mathrm{c}$ and lipid peroxidation in hepg2 cells. Prostaglandins Leukot Essent Fatty Acids 60:367-370

31. Haag M, Vermeulen F, Magada O, Kruger MC 1999 Polyunsaturated fatty acids inhibit $\mathrm{Mg}^{2+}$-ATPase in basolateral membranes from rat enterocytes. Prostaglandins Leukot Essent Fatty Acids 61:25-27

32. Rusyn I, Bradham CA, Cohn L, Schoonhoven R, Swenberg JA, Brenner DA, Thurman RG 1999 Corn oil rapidly activates nuclear factor- $\kappa$ b in hepatic Kupffer cells by oxidant-dependent mechanisms. Carcinogenesis 20:2095-2100

33. Akisu M, Baka M, Coker I, Kultursay N, Huseyinov A 1998 Effect of dietary n-3 fatty acids on hypoxia-induced necrotizing enterocolitis in young mice. N-3 fatty acids alter platelet-activating factor and leukotriene $\mathrm{B}_{4}$ production in the intestine. Biol Neonate 74:31-38

34. MacKendrick W, Caplan M, Hsueh W 1993 Endogenous nitric oxide protects agains platelet-activating factor-induced bowel injury in the rat. Pediatr Res 34:222-228

35. Kubes P, Arfors KE, Granger DN 1991 Platelet-activating factor-induced mucosal dysfunction: role of oxidants and granulocytes. Am J Physiol 260:G965-G971

36. Otamiri T, Lindahl M, Tagesson C 1988 Phospholipase A2 inhibition prevents mucosal damage associated with small intestinal ischaemia in rats. Gut 29:489-494

37. Hsueh W, Gonzalez-Crussi F 1988 Ischemic bowel necrosis induced by plateletactivating factor: an experimental model. Methods Achiev Exp Pathol 13:208-239

38. Huang L, Tan X, Crawford SE, Hsueh W 1994 Platelet-activating factor and endotoxin induce tumour necrosis factor gene expression in rat intestine and liver. Immunology 83:65-69

39. Hsueh W, Gonzalez-Crussi F, Arroyave JL 1986 Platelet-activating factor-induced ischemic bowel necrosis. An investigation of secondary mediators in its pathogenesis. Am J Pathol 122:231-239 